\title{
Mapeamento da produção acadêmica sobre gestão ambiental e comunidades
}

\section{tradicionais}

\author{
Mapping academic production on environmental management and traditional communities \\ Mapeo de la producción académica sobre gestión ambiental y comunidades tradicionales
}

Recebido: 27/09/2021 | Revisado: 02/10/2021 | Aceito: 05/10/2021 | Publicado: 09/10/2021

\author{
Larissa Sousa Fernandes \\ ORCID: https://orcid.org/0000-0002-2707-7206 \\ Universidade Federal de Campina Grande, Brasil \\ E-mail: larasousa8@hotmail.com \\ Erivaldo Moreira Barbosa \\ ORCID: https://orcid.org/0000-0001-7479-1827 \\ Universidade Federal de Campina Grande, Brasil \\ E-mail: erifat@terra.com.br \\ Maria de Fátima Nóbrega Barbosa \\ ORCID: https://orcid.org/0000-0003-3415-8829 \\ Universidade Federal de Campina Grande, Brasil \\ E-mail: mfnobregabarbosa@gmail.com
}

\begin{abstract}
Resumo
Este artigo tem por objetivo fazer um mapeamento da produção acadêmica que relaciona gestão ambiental e comunidades tradicionais, através de análise bibliométrica. Para tanto, foi feito um levantamento dos artigos científicos publicados em periódicos entre os anos de 2007 a 2021 na base de dados da Web of Science, bem como por meio do software VOSviewer, que apresentou as redes de autoria e coautoria, países, organizações e ocorrência de palavras-chave a partir dos dados compilados na WoS. As comunidades tradicionais são formadas em sua maioria por povos nativos que preservaram seu território e cultura, resistindo a séculos de colonização, preservando de maneira especial o meio ambiente em seu entorno, dado que, para tais povos, ele possui um valor que transcende o econômico: além de prover sua subsistência, reproduz sua cultura, valores e crenças. Por esse motivo, organismos internacionais, a exemplo da Organização Mundial do Trabalho e do Banco Mundial consideram a preservação dessas comunidades fundamental para o desenvolvimento socioambiental, tendo em vista que seus conhecimentos podem contribuir com novas formas de aprendizado para o manejo sustentável dos recursos naturais. Nesse sentido, a pesquisa identificou diversas produções acerca da gestão ambiental e comunidades tradicionais, cuja análise dos dados obtidos pela WoS e pelo VOSviewer revelou o protagonismo destas comunidades numa gestão comprometida com a preservação do meio ambiente, com destaque para pesquisas que focaram no desenvolvimento sustentável, na manutenção da biodiversidade e na aplicação dos conhecimentos da tradição na gestão.
\end{abstract}

Palavras-chave: Comunidades tradicionais; Gestão ambiental; Análise bibliométrica.

\begin{abstract}
The present article aims to map the academic production relating environmental management and traditional communities through bibliometric analysis. In order to do so we compiled scientific articles published between the years 2007 and 2021 using the Web of science database and the VOSviewer software that allows for authors, coauthors, countries, organizations and key-words search. Traditional communities are mostly comprised by native people that exist preserving both original territory and culture. Their resistance to centuries of colonization is possible by means of their unique relationship with their surrounding environment as for them nature is extremely valuable beyond economical factors. Nature provides for them physically but also to their beliefs and culture. For that reason, international organizations like the International Labour Organization and the World bank consider the preservation of such communities fundamental for the socio environmental development since their knowledge of nature can be useful for the development of new eco friendly ways of using natural resources. On that subject, our research identified many papers on environmental management and traditional communities that revealed these communities take the lead on environmentally engaged management, specially in researches focused on sustainable development, biodiversity maintenance and traditional knowledge applied.
\end{abstract}

Keywords: Traditional communities; Environmental management; Bibliometric analysis.

\section{Resumen}

Este artículo tiene como objetivo mapear la producción académica que relaciona la gestión ambiental y las comunidades tradicionales através del análisis bibliométrico. Para ello, se realizó una encuesta de artículos científicos 
publicados en revistas entre 2007 y 2021 en la base de datos Web of Science, así como através del software vosviewer, que presentó las redes de autoría y coautoría, países, organizaciones y ocurrencia de palabras clave a partir de los datos compilados en WoS. Las comunidades tradicionales están formadas en su mayoría por pueblos originarios que han preservado su territorio y cultura, resistiendo siglos de colonización, preservando de manera especial el medio ambiente en su entorno, ya que, para tales pueblos, tiene un valor que trasciende lo económico: además de proporcionar su subsistencia, reproduce su cultura, valores y creencias. Por esta razón, organismos internacionales, como la Organización Mundial del Trabajo y el Banco Mundial consideran que la preservación de estas comunidades es fundamental para el desarrollo socioambiental, considerando que sus conocimientos pueden contribuir a nuevas formas de aprendizaje para el manejo sostenible de los recursos naturales. En este sentido, la investigación identificó varias producciones sobre gestión ambiental y comunidades tradicionales, cuyo análisis de los datos obtenidos por WoS y VOSviewer reveló el protagonismo de estas comunidades en una gestión comprometida con la preservación del medio ambiente, con énfasis en investigaciones que se centraron en el desarrollo sostenible, el mantenimiento de la biodiversidad y la aplicación de conocimiento de la tradición en la gestión.

Palabras clave: Comunidades tradicionales; Gestión ambiental; Análisis bibliométrico.

\section{Introdução}

Comunidades e povos tradicionais são definidos como grupos que ocupam um determinado território e possuem características sociais, culturais e econômicas próprias. Estes grupos estão espalhados por todo mundo, sendo boa parte deles nativos de uma determinada região, estando ali antes do processo de colonização, como a população indígena nos países da América Latina e os aborígenes australianos, por exemplo; como também por povos que se estabeleceram posteriormente, a exemplo das chamadas "comunidades remanescentes de quilombos", no Brasil, os antigos quilombos, formados por escravos fugidos, que se firmaram em um território e vêm historicamente, através dos seus descendentes, lutando por reconhecimento.

Todas estas comunidades espalhadas pelo mundo possuem uma importante característica em comum, qual seja a relação sociometabólica com o meio em que vivem, visto compreenderem que existe uma interdependência entre homem e natureza de modo que o equilíbrio de sua construção social, cultural e econômica depende do equilíbrio ambiental. Desse modo, suas tradições acompanham e dependem dos ciclos naturais.

Por esta razão, as comunidades tradicionais são extremamente relevantes para a preservação do meio ambiente. Os modos de vida desses povos devem ser respeitados e seus conhecimentos não devem ser desprezados. Prova disso é que, mesmo diante de tantas mudanças históricas e interferências em suas culturas, as comunidades tradicionais ainda são responsáveis pela preservação da biodiversidade em diversas partes do planeta (Toledo, 1999).

É nesse sentido que diversos organismos internacionais colocam em pauta a importância dessas comunidades, recomendando aos países signatários que respeitem estes povos e atuem de modo a construir políticas públicas que visem a sua proteção, numa gestão que esteja voltada ao desenvolvimento sustentável.

Contudo, é preciso que se compreenda a sustentabilidade não como um conhecimento exterior a ser empregado naquele espaço, mas pela manutenção de um conhecimento que muitas vezes supera o conhecimento científico, visto que nesses casos se embasa em um conhecimento muito mais aprofundado pela vivência que perpassa gerações dentro daquele território e do manejo dos recursos naturais ali inseridos.

Diante desse contexto, este artigo tem como objetivo realizar análise bibliométrica - método que analisa quantitativamente a produção acadêmica em determinada área do conhecimento - da produção científica internacional acerca das comunidades tradicionais e sua relação com a gestão ambiental, utilizando a base de dados da Web of Science e o software VOSviewer, que indicam autores, países, instituições, palavras-chave, entre outros dados, buscando compreender como tem se orientado estas produções científicas e qual seu alcance. 


\section{As comunidades tradicionais e a gestão ambiental}

\subsection{Convenção n¹69/1989 da OIT e o reconhecimento das comunidades tradicionais na preservação do meio ambiente}

A Convenção $n^{\circ}$ 169/1989 da Organização Internacional do Trabalho, que dispõe sobre povos indígenas e tribais, define estes primeiros como aqueles que estavam presentes em um determinado território antes do processo colonizatório, enquanto que povos tribais se caracterizam, assim como os povos indígenas, enquanto comunidades que possuem tradições, instituições políticas e religiosas, linguagens e costumes próprios. Este documento reconhece a discriminação existente em relação a estas comunidades, buscando orientar os países a pensarem legislações específicas que respeitem, protejam e preservem suas linguagens, territórios, identidades e tradições, desde que estas não firam as leis e os direitos fundamentais (Arts. $3^{\circ}, 4^{\circ}$ e $5^{\circ}$ ), construindo estes dispositivos jurídicos a partir da consulta e constante participação destes povos, num reconhecimento de que apenas eles podem protagonizar o debate acerca de seus interesses.

Vale salientar que este documento explicita a necessidade de integralização das comunidades com a sociedade civil, o que significa dizer que o reconhecimento destas comunidades a partir de suas especificidades jamais deve implicar em isolamento das mesmas, com consequente afastamento da sociedade, mas o contrário, tal reconhecimento deve fortalecer a integralização destas diferenças em prol de uma sociedade plural, garantindo a todos aqueles que fazem parte destes espaços o direito à cidadania, o acesso a todos os direitos e deveres inerentes a todo e qualquer cidadão, como saúde, educação, emprego, seguridade social, entre outros.

O debate em torno do conceito de povos e comunidades tradicionais culminou, no âmbito do Banco Mundial (a partir da Diretiva Operacional 4.20 de 1991), no uso do termo "povos nativos" (indigenous), que compreende em seu escopo características específicas de povos que habitam determinadas áreas. Estas características abarcam questões como pertença a um território e cultura específica, conhecimentos e valores sociais oriundos da tradição e produção voltada principalmente para subsistência.

Um ponto de destaque presente em todos os documentos destes órgãos e entidades relativos às comunidades e povos tradicionais é sobre a integralização desses grupos com o meio ambiente, no qual a reprodução de suas tradições, sociedade e cultura está intrinsecamente atrelada pelo manejo dos recursos naturais presentes em seu território, numa relação que não se estabelece pela necessidade de explorar recursos para obtenção de lucro, mas dada pela compreensão da dependência que existe em relação aos ciclos presentes na natureza para a manutenção do equilíbrio. (Diegues, 2000)

Todo esse processo de identificação com o meio ambiente se constrói a partir da representação, pela cultura e religiosidade, dos seus mitos e símbolos. Os conhecimentos dos povos tradicionais são oriundos da representação simbólica e do conhecimento adquirido empiricamente, o que viabilizou todo um sistema de manejo sustentável e preservação do meio ambiente: "Um aspecto relevante na definição de culturas tradicionais é a existência de sistemas de manejo dos recursos naturais marcados pelo respeito aos ciclos naturais, à sua exploração dentro da capacidade de recuperação das espécies de animais e plantas utilizadas. Esses sistemas tradicionais de manejo não são somente formas de exploração econômica dos recursos naturais, mas revelam a existência de um complexo de conhecimentos adquiridos pela tradição herdada dos mais velhos, de mitos e símbolos que levam à manutenção e ao uso sustentado dos ecossistemas naturais” (Diegues, 2000, p.84-85).

Nesse sentido, é interessante observar como locais considerados “sagrados" por certos povos são tidos dessa maneira pela necessidade real de preservação, onde a sacralidade ali empregada se dá mediante a compreensão da importância daquele lugar para o equilíbrio e manutenção de um ciclo sem o qual aquela comunidade não sobreviveria. Diegues (2000) cita um estudo de Bourgoignie (1972) no qual este revela como uma interdição imposta aos pescadores Tofinu, do ex Daomé (onde hoje se situa o Benim), foi fundamental para preservar áreas de reprodução de peixes. Segundo os nativos, as áreas onde ocorriam esta reprodução eram lugar de descanso da deusa Anasi Gbégu, o que impediu a ocorrência de um desequilíbrio. 
Bourgoigne também mostra como, ao serem inseridos na economia de mercado, os Tofinu perderam traços de sua cultura, e seus locais sagrados foram profanados, acarretando um desequilíbrio socioambiental: "A desorganização sóciocultural deixou caminho livre para uma tecnologia destinada a usar os recursos do lago Nokoné de maneira sempre mais individualista e anárquica. A pressão econômico-ecológica levou à redução quantitativa e qualitativa das proibições tradicionais de pesca e à profanação dos lugares sagrados e preservados. Os lugares santos, em sua grande maioria, desapareceram e seus símbolos foram devorados pelo sal das águas salobras, e os santuários foram profanados e abandonados pelos homens" (Bourgoigne, 1972, p. 429 apud Diegues, 2000, p. 86)

Nesta perspectiva, é primordial compreender que a manutenção das culturas nas comunidades tradicionais define sua existência, precisamente no aspecto em que é através dessa cultura que se dá a simbiose entre comunidade e natureza, construindo um modo de vida sustentável, mas não se afirma com isso que uma cultura deva estar em seu estado "puro", o que não nem seria possível, visto que a cultura não é estática, mas se modifica com o tempo. Quando se fala em tradição, não se quer remeter a algo primitivo, imutável.

O conhecimento tradicional é diverso e mutável e os povos e comunidades tradicionais acompanham o processo histórico no qual estão inseridos. Por esses motivos, e diante do contexto de colonização e do advento do modo de produção capitalista vigente, que absorve e afeta todas as culturas, as culturas das comunidades tradicionais acabam sendo transformadas em mercadoria, têm sua essência e origem alteradas, sendo uniformizadas e massificadas pelo processo de globalização. (Peet, 1986 apud Diegues, 2000, p. 92).

Constata-se, nesse sentido, a dependência, em menor ou maior escala, das comunidades tradicionais em relação às demandas inerentes às necessidades de mercado, que afetam sua relação com o meio ambiente, com os demais indivíduos e com seu meio de vida. Esta é a razão pela qual muitas comunidades têm buscado historicamente organizar-se no sentido de retomar sua identidade e território, a fim de regularizar seu espaço, para que não fiquem expostos a grupos que possam vir a disputar poder de forma desproporcional, com posterior perda desse território e, consequentemente, da sua identidade e sustento.

\subsection{O Decreto $\mathrm{n}^{\circ} 6.040$ de 07 de fevereiro de 2007 e a organização das comunidades tradicionais no Brasil}

O Brasil, em sua Constituição de 1988, já traz a proteção a comunidades indígenas no art. 231, e no art. 216 ao tratar do patrimônio cultural, cita em seu $\S 5^{\circ}$ "sítios remanescentes de quilombos", o que já pode ser considerado um reconhecimento a essas populações (Brasil, 2016).

Contudo, o movimento político organizado mais relevante em torno dessa pauta se deu anos mais tarde pela união de diversos movimentos sociais e sociedade civil a partir de 2004, com a formação da Comissão Nacional de Desenvolvimento Sustentável das Comunidades Tradicionais (Decreto no 10408 de 27/12/2004), abarcando comunidades para além das citadas na Constituição, quando estes grupos promoveram a realização do I Encontro Nacional de Comunidades Tradicionais: Pautas para Políticas Públicas. O evento, que ocorreu de 17 a 19 de agosto de 2005, culminou na reformulação desta comissão, de onde se elaborou a Política Nacional de Desenvolvimento Sustentável para Povos e Comunidades Tradicionais, instituída pelo Decreto ${ }^{\circ} 6.040$, de 07 de fevereiro de 2007. (Thum, 2017)

Este marco legal apresenta a definição do que se entende, no Brasil, por Povos e Comunidades Tradicionais: "grupos culturalmente diferenciados e que se reconhecem como tais, que possuem formas próprias de organização social, que ocupam e usam territórios e recursos naturais como condição para sua reprodução cultural, social, religiosa, ancestral e econômica, utilizando conhecimentos, inovações e práticas gerados e transmitidos pela tradição". (Brasil, 2007).

A Política Nacional de Desenvolvimento Sustentável para Povos e Comunidades Tradicionais traz em seu escopo o reconhecimento da diversidade de comunidades e a necessidade da inclusão destas na formação de políticas públicas, 
especialmente no que tange à proteção de seus territórios, conceituando-os enquanto "espaços necessários à reprodução cultural, social e econômica dos povos e comunidades tradicionais, sejam eles utilizados de forma permanente ou temporária, observado, no que diz respeito aos povos indígenas e quilombolas, respectivamente, o que dispõem os arts. 231 da Constituição e 68 do Ato as Disposições Constitucionais Transitórias e demais regulamentações. (Brasil, 2007).

Assim delimitado, o território se apresenta enquanto um importante espaço na garantia dos direitos sociais destas comunidades, sendo a principal causa dos conflitos e marginalização desses povos. Por este motivo, existe uma busca constante dessas comunidades em manter-se e proteger seus interesses, visto que o progresso pautado pela ação de um pensamento que insiste em se colocar enquanto colonizador traz desequilíbrio aos seus modos de vida, para o meio no qual estão inseridos e para o meio ambiente de modo geral.

Preservar e inserir as comunidades tradicionais na gestão ambiental é um caminho importante para o desenvolvimento sustentável e as pesquisas que apresentam esta correlação contribuem para apresentar novos caminhos e práticas para preservação ambiental.

\section{Metodologia}

O método utilizado para mapear a produção acadêmica internacional acerca da gestão ambiental em comunidades tradicionais foi a análise bibliométrica, que, segundo Tague-Sutckiffe (apud Vanti, 2002, p.154) se configura enquanto "[...] o estudo dos aspectos quantitativos da produção, disseminação e uso da informação registrada. A bibliometria desenvolve padrões e modelos matemáticos para medir esses processos, usando seus resultados para elaborar previsões e apoiar tomadas de decisões".

A análise em tela foi realizada no dia 11 de fevereiro de 2021, às 13h, cuja pesquisa foi feita pelo site dos periódicos capes, onde constam diversas bases de periódicos e a partir do qual foi escolhida a base Web of Science (Clarivate Analytics).

Por meio da delimitação dos índices de classificação, palavras-chave e tempo estipulado, foi feita uma filtragem de categorias com base nos resultados, conforme tabela a seguir:

Quadro 1 - Delimitação Da Pesquisa Na Web Of Science.

\begin{tabular}{|c|c|c|c|c|c|}
\hline Índices & Palavras-chave & $\begin{array}{l}\text { Tempo } \\
\text { Estipulado }\end{array}$ & Áreas & Tipo & Idiomas \\
\hline $\begin{array}{l}\text { - Science } \\
\text { Citation Index } \\
\text { Expanded (SCI- } \\
\text { EXPANDED) } \\
\text { - Social Sciences } \\
\text { Citation Index } \\
\text { (SSCI) } \\
\text { Emerging } \\
\text { Sources } \\
\text { Citation Index } \\
\text { (ESCI) }\end{array}$ & $\begin{array}{l}\text { - } \quad \text { "environmental } \\
\text { management" } \\
\text { "indigenous } \\
\text { people" } \\
\text { - "quilombos", } \\
\text { - "quilombolas" } \\
\text { "traditional } \\
\text { peoples and } \\
\text { communities" } \\
\text { "traditional } \\
\text { Community" } \\
\text { "traditional } \\
\text { pleoples" }\end{array}$ & $2007-2021$ & $\begin{array}{ll}\text { - } & \text { environmental } \\
\text { - } & \text { sciences } \\
\text { environmental } & \text { studies } \\
\text { - } & \text { public } \\
\text { - } & \text { social sciences } \\
\text { - } & \text { interdisciplinary } \\
\text { - development } \\
\text { - } \\
\text { studies } \\
\text { management }\end{array}$ & Artigos & $\begin{array}{l}\text { Inglês } \\
\text { Português }\end{array}$ \\
\hline
\end{tabular}

Fonte: Elaborado pelos autores (2021).

A partir da escolha dos índices, palavras-chave e tempo estipulado, a base de dados apresentou um total de 751 artigos, os quais foram refinados por área, tipo e idioma ( $c f$. Quadro I), resultando em 93 registros. A partir desses resultados, 
foi realizada a análise pela própria base da Web of Science (WoS), que gerou um mapa de área, barra de resultados e um arquivo em formato .txt com o registro de todo o conteúdo pesquisado para utilização no software VOSwiewer version 1.6.16 (software usado para demonstrar, através de agrupamentos, chamados aqui de clustering, as conexões existentes entre as produções acadêmicas identificadas na pesquisa realizada na base Web of Science).

A plataforma WoS e o VOSviewer apresentam dados como palavras-chave, países, instituições, etc., apresentando um mapeamento da produção, o que possibilita analisar os rumos e encadeamentos da pesquisa na área de gestão ambiental relacionada às comunidades tradicionais.

\section{Resultados e Discussão}

A pesquisa em tela identificou, após filtragem já apresentada na metodologia, um total de 93 publicações indexadas na biblioteca principal da Web of Science, abordando a questão da gestão ambiental em comunidades tradicionais. De acordo com os resultados apresentados mediante gráficos e tabelas geradas na base da $W o S$, verificou-se uma soma de 1045 citações, uma média de 11,24 citações por publicação, conforme gráfico, apresentado na Figura 1, a seguir:

Figura 1 - Número de citações.

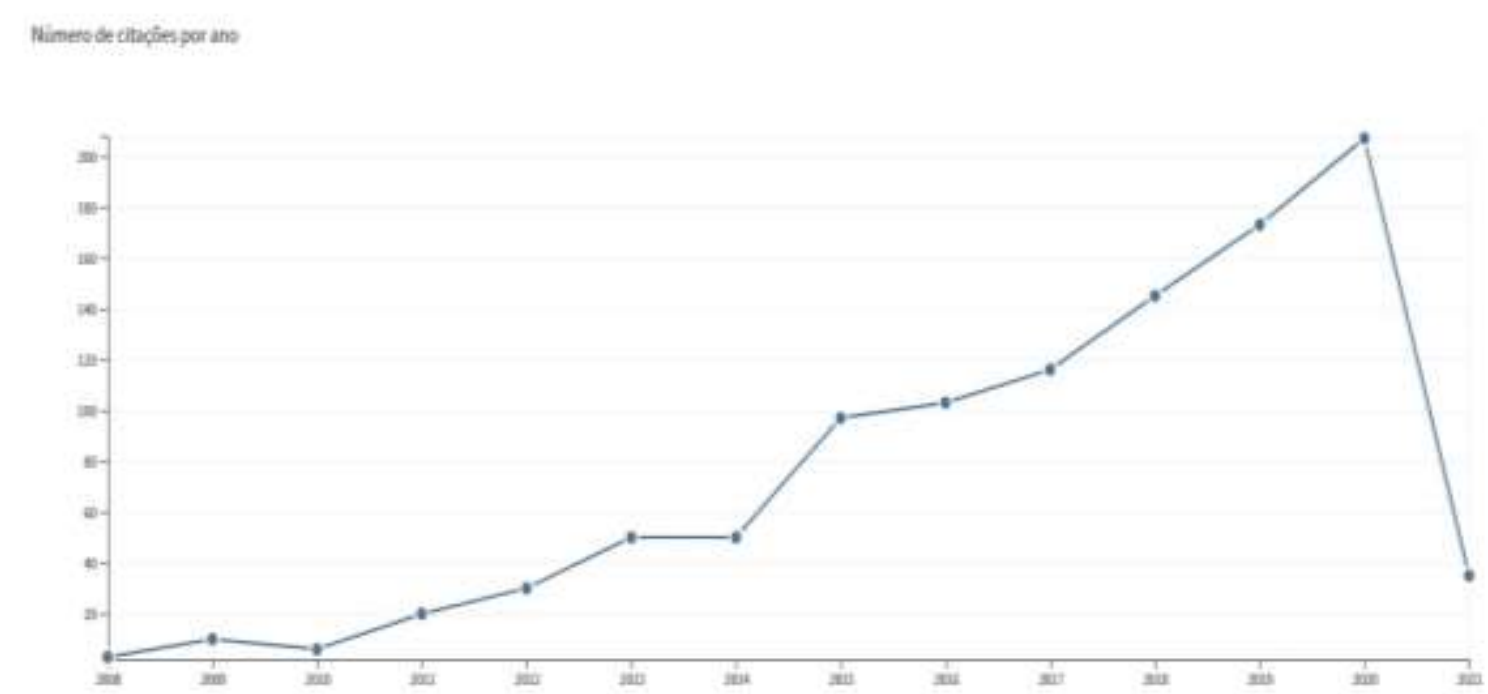

Fonte: Elaborado pelos autores (2021).

No gráfico acima, percebe-se o crescimento exponencial de citações, havendo uma queda de 2020 para 2021 devido ao fato de a pesquisa ter sido realizada no mês de fevereiro. Este crescimento acompanha o número de produções durante o período escolhido (2007-2021), em que os anos de 2014 (10 produções), 2018 (12 produções), 2019 (20 produções) e 2020 (14 produções) se destacam, demonstrando como o tema tem crescido em relevância. $\mathrm{O}$ gráfico de barras expresso na Figura 2, gerado a partir da pesquisa no $W o S$, demonstra bem este crescimento: 
Figura 2 - Itens publicados por ano.

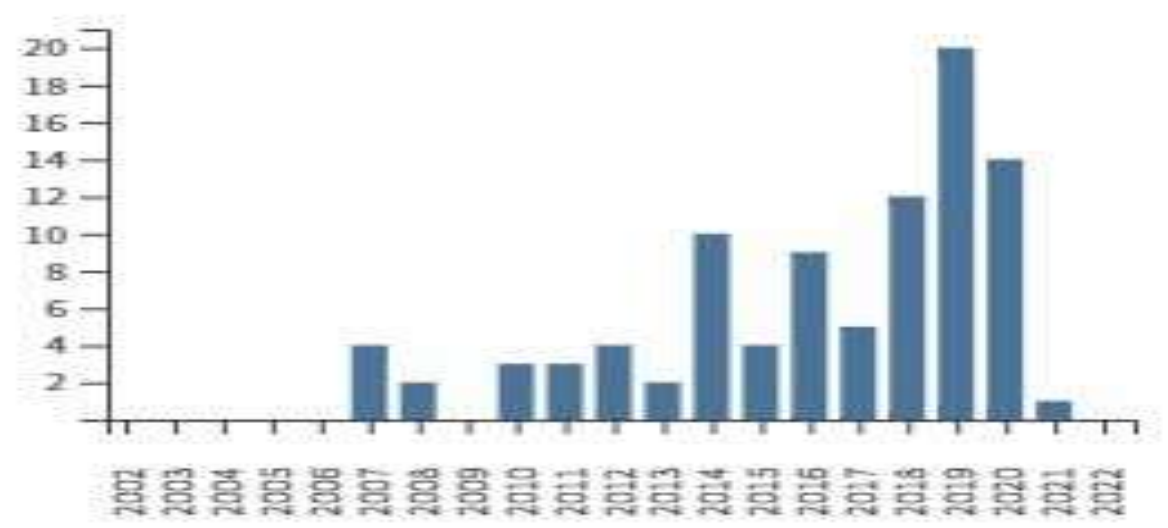

Fonte: Elaborado pelos autores (2021).

A escolha das palavras-chave para a pesquisa levou em conta o que documentos oficiais e pesquisadores na área consideram por comunidades e povos tradicionais, seguindo as diretrizes da Organização Internacional do Trabalho (OIT), o Banco Mundial e por fim o marco legal brasileiro, que define povos e comunidades tradicionais no Decreto 6.040 de 07 de fevereiro de 2007.

É importante salientar que o Marco Legal Brasileiro foi fonte de delimitação do período a ser pesquisado, bem como dos idiomas das publicações, tendo em vista o papel estratégico do Brasil na conservação da sociobiodiversidade, por apresentar uma grande variedade destas comunidades, fato que se verificou, também, na quantidade de publicações por país, onde o Brasil corresponde $25.806 \%$ do total de citações, ficando à frente dos Estados Unidos (21.505\%), Austrália (13.978\%) e Canadá (11.828\%), como pode ser observado na Figura 3:

Figura 3 - Países/ Regiões.

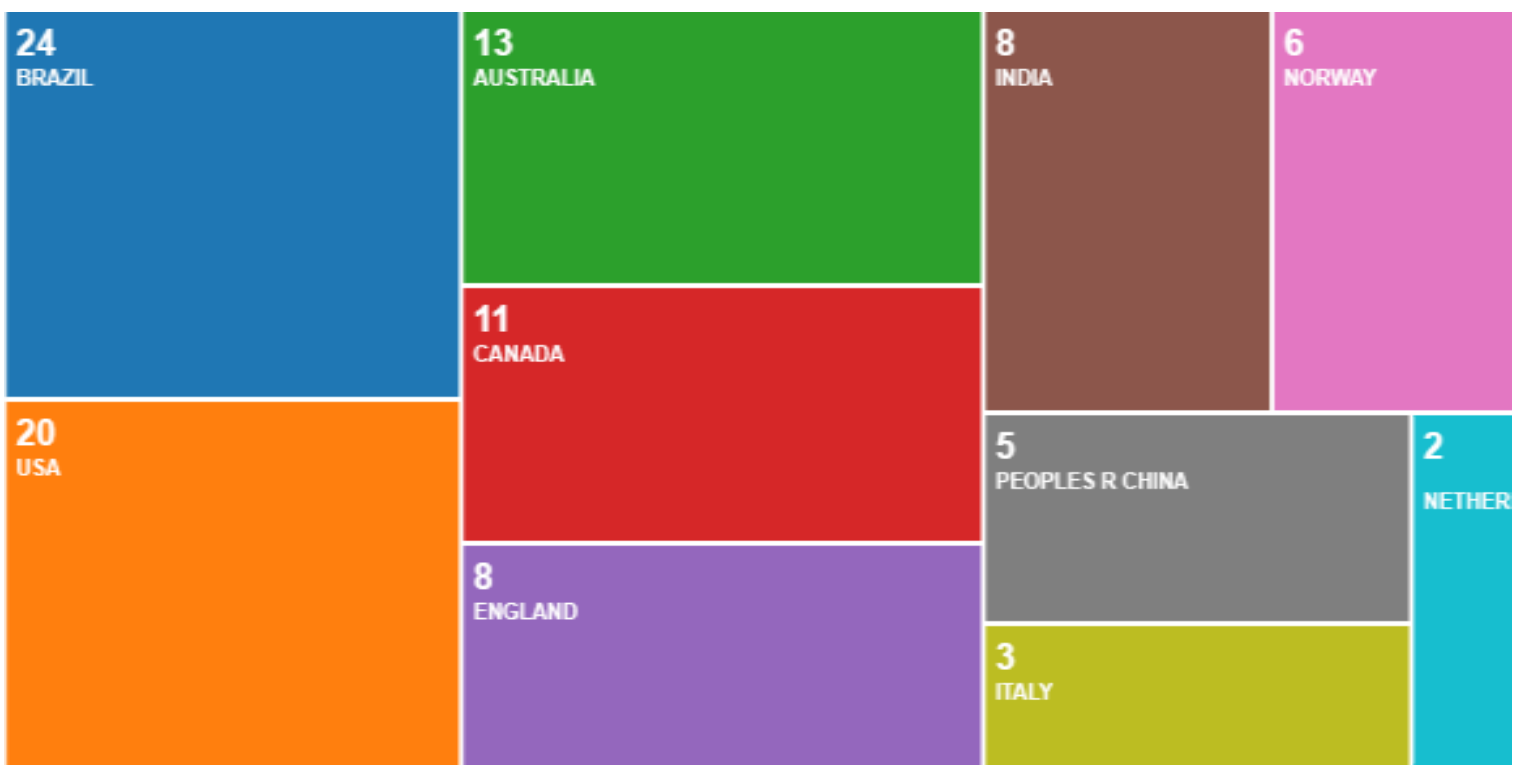

Fonte: Elaborado pelos autores (2021). 
No que se refere aos principais periódicos, foram apresentados um total de 39 periódicos, sendo o mais relevante o Desenvolvimento e Meio Ambiente, com 7 publicações (7.527\%), seguido do Ecology and Society, com 5 publicações (5.376\%), Biodiversity and conservation, com 4 publicações (4.301\%), Journal of peasant studies, também com 4 publicações (4.301\%) e Local environment com 3 publicações (3.226\%). Mais 12 periódicos continham 2 publicações, (2,151\% cada), e os demais com 1 publicação (1,075 cada).

Em seguida, será observada a análise da rede de coautoria mediante o uso do software Vosviewer, com base na qual será verificada a relevância de autores e ocorrência de palavras-chave, apresentando estatisticamente a configuração do tema pesquisado. Desse modo, será apresentada a co-ocorrência de autores, onde pode-se verificar aqueles que são mais citados e os que possuem mais relevância de laços de força na rede (Van Eck, 2017).

A partir da pesquisa no Vosviewer, obteve-se um mapa bibliométrico amplo, onde aparecem todos os autores com pelo menos uma publicação, o que totalizou 326 autores. A rede apresenta um total de 83 clusters, contudo apenas 10 autores aparecem conectados, como pode-se observar na Figura 4:

Figura 4 - Rede de co-autoria por autores.

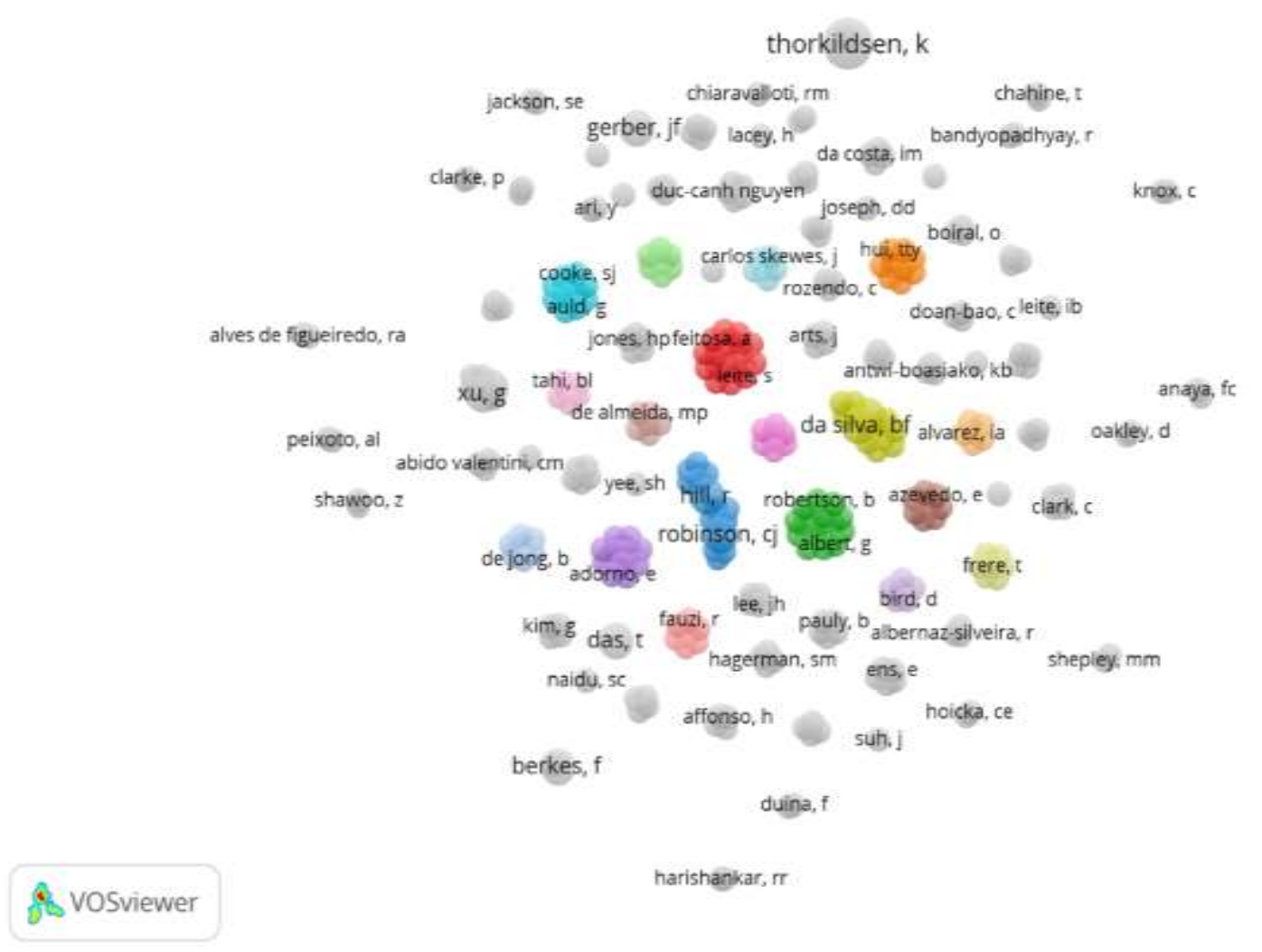

Fonte: Elaborado pelos autores (2021).

Observa-se aqui um mapa amplo que evidencia 807 links entre os autores e 5 clusters principais. A correlação de força maior entre autores pode-se observar no cluster $1 \mathrm{em}$ vermelho, onde os 15 autores (Feitosa, M. et al., 2021) apresentaram relação de força 14. Contudo, nenhum possui citações e todos apresentaram 1 publicação.

O cluster 2, em verde, por sua vez, apresenta todos os 14 autores (Albert, G. et. al., 2016) com relação de força 13, todos com 10 citações e também todos com 1 publicação. Já no cluster 3, em azul mais escuro, temos 14 autores, de onde se 
destacam Hill, R., apresentando relação de força 10, 117 citações e 2 publicações, e Robinson, C.J., com relação de força 8, 77 citações e 2 publicações.

O cluster 4, em verde claro, apresenta 12 autores, destacando-se Da Silva e Vacchi, ambos apresentando relação de força 12, 47 citações e 2 publicações. Por fim, o cluster 5, em roxo, apresenta 11 autores (Adorno, E. et. al), onde todos possuem relação de força 10,1 citação e 1 publicação.

Em relação aos autores mais citados, verificou-se que aquele com maior número de citações aparece isolado no cluster de relação de força por coautoria, qual seja Berkes, F., apresentando força 1, 2 documentos e 201 citações. Já o segundo autor, Hill, R., aparece com 117 citações, 2 documentos e força 10, conforme tabela a seguir:

Figura 5 - Autores por citação.

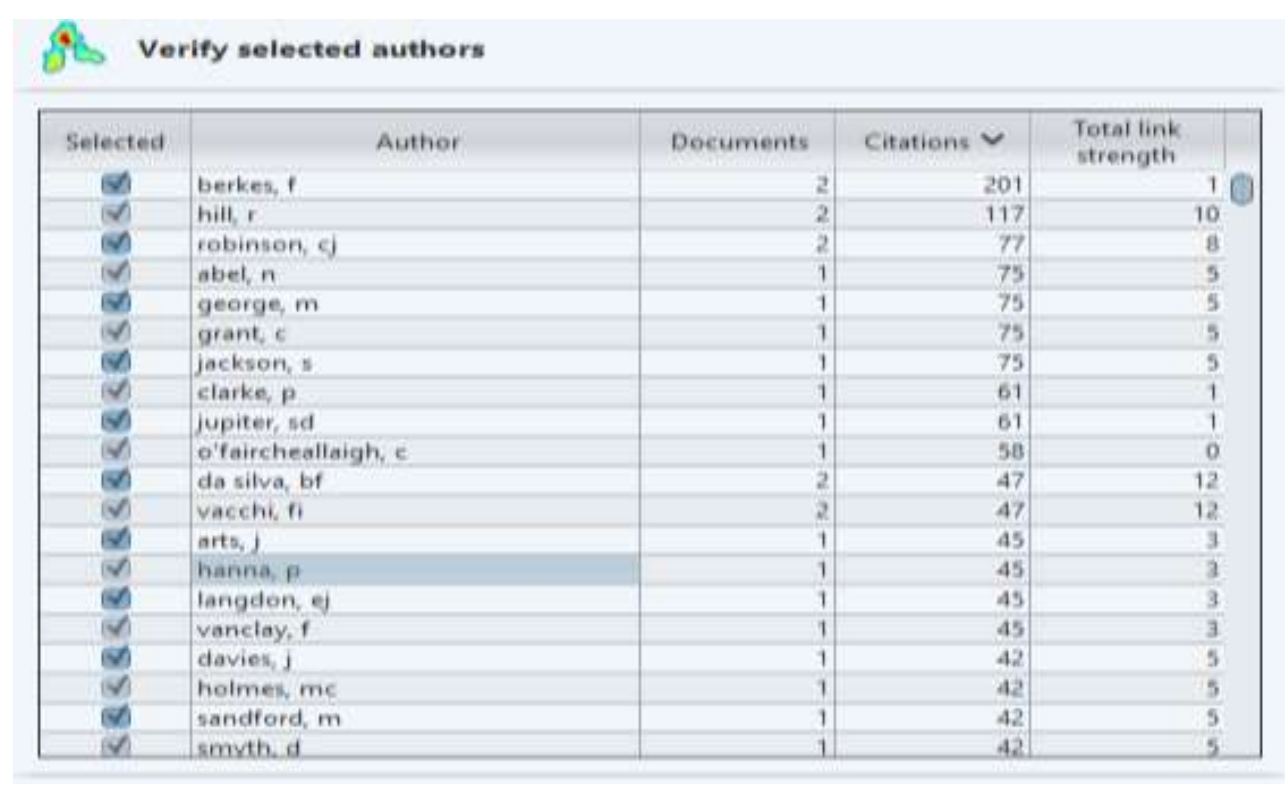

Fonte: Elaborado pelos autores (2021).

Outro ponto analisado foi a relação entre os países onde houve mais publicações, confirmando o papel de destaque do Brasil na área pesquisada. Conforme as figuras 6 e 7, o Brasil aparece no cluster com força 8, 24 publicações e 189 citações, sendo o primeiro em número de publicações, atrás apenas de Canadá e Austrália em termos de citações, e atrás dos EUA e Canadá em relação de força: 
Figura 6 - Países com pelo menos 5 publicações.

Figura 7 - Países com pelo menos 5 publicações.

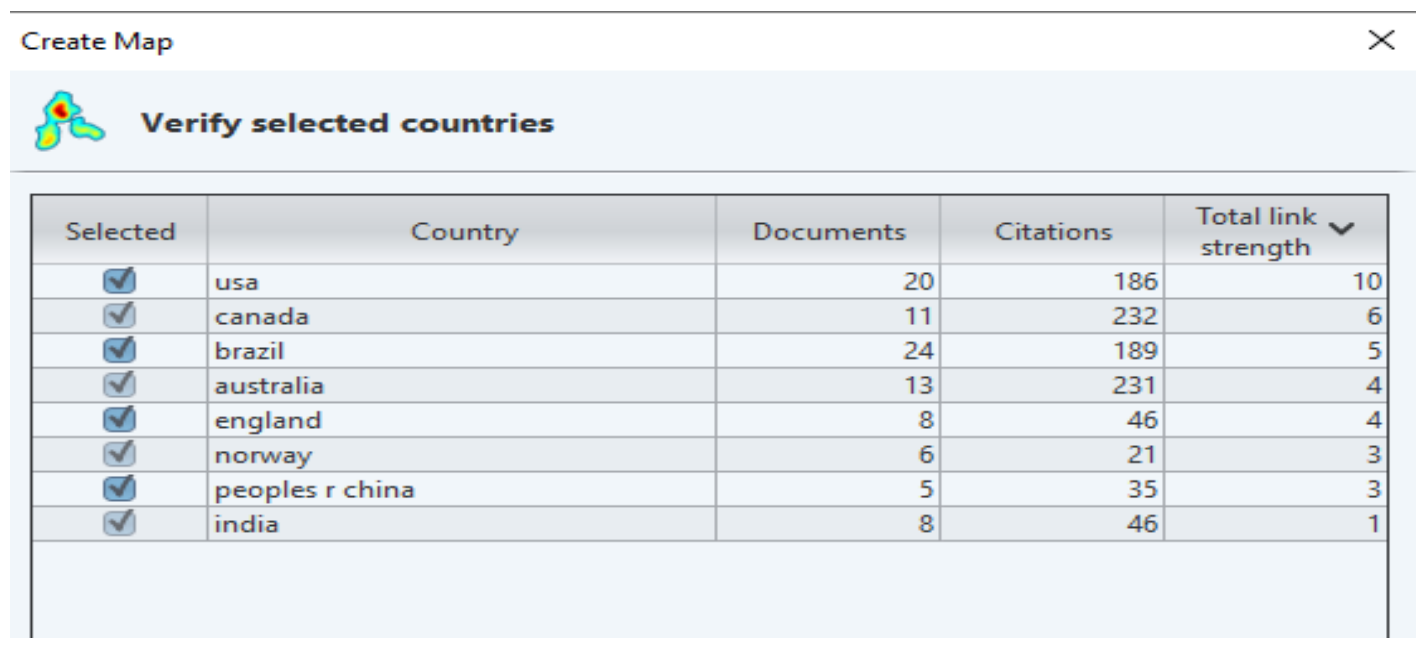

Fonte: Elaborado pelos autores (2021).

Por último, foi verificada a ocorrência de palavras-chave. De 712 palavras-chave identificadas, este número foi filtrado para as palavras com pelo menos 5 ocorrências, chegando a um total de 18. Na Figura 8, pode-se verificar quais foram essas palavras-chave e a ocorrência. Na figura 9, tais palavras são apresentadas em dois clusters: 
Research, Society and Development, v. 10, n. 13, e141101321116, 2021

(CC BY 4.0) | ISSN 2525-3409 | DOI: http://dx.doi.org/10.33448/rsd-v10i13.21116

Figura 8 - Ocorrência de palavras-chave.

\section{Verify selected keywords}

\begin{tabular}{|c|c|c|c|}
\hline Selected & Keyword & Occurrences & $\begin{array}{l}\text { Total link } \\
\text { strength }\end{array}$ \\
\hline 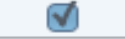 & conservation & 15 & 37 \\
\hline$\sqrt{ }$ & management & 15 & 37 \\
\hline$\nabla$ & knowledge & 10 & 25 \\
\hline$\sqrt{ }$ & governance & 9 & 23 \\
\hline$\nabla$ & biodiversity & 8 & 19 \\
\hline$\sqrt{ }$ & resilience & 5 & 19 \\
\hline$\nabla$ & fisheries & 5 & 18 \\
\hline$\sqrt{ }$ & community & 6 & 16 \\
\hline$\nabla$ & indicators & 5 & 15 \\
\hline$\sqrt{ }$ & communities & 7 & 14 \\
\hline$\nabla$ & science & 5 & 12 \\
\hline$\sqrt{ }$ & indigenous & 5 & 11 \\
\hline 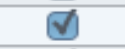 & brazil & 5 & 10 \\
\hline$\checkmark$ & politics & 7 & 10 \\
\hline 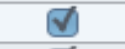 & sustainability & 5 & 10 \\
\hline$\sqrt{ }$ & biodiversity conservation & 6 & 9 \\
\hline$\nabla$ & participation & 7 & 8 \\
\hline$\sqrt{ }$ & canada & 5 & 7 \\
\hline
\end{tabular}

Fonte: Elaborado pelos autores (2021).

Figura 9 - Ocorrência de palavras-chave.

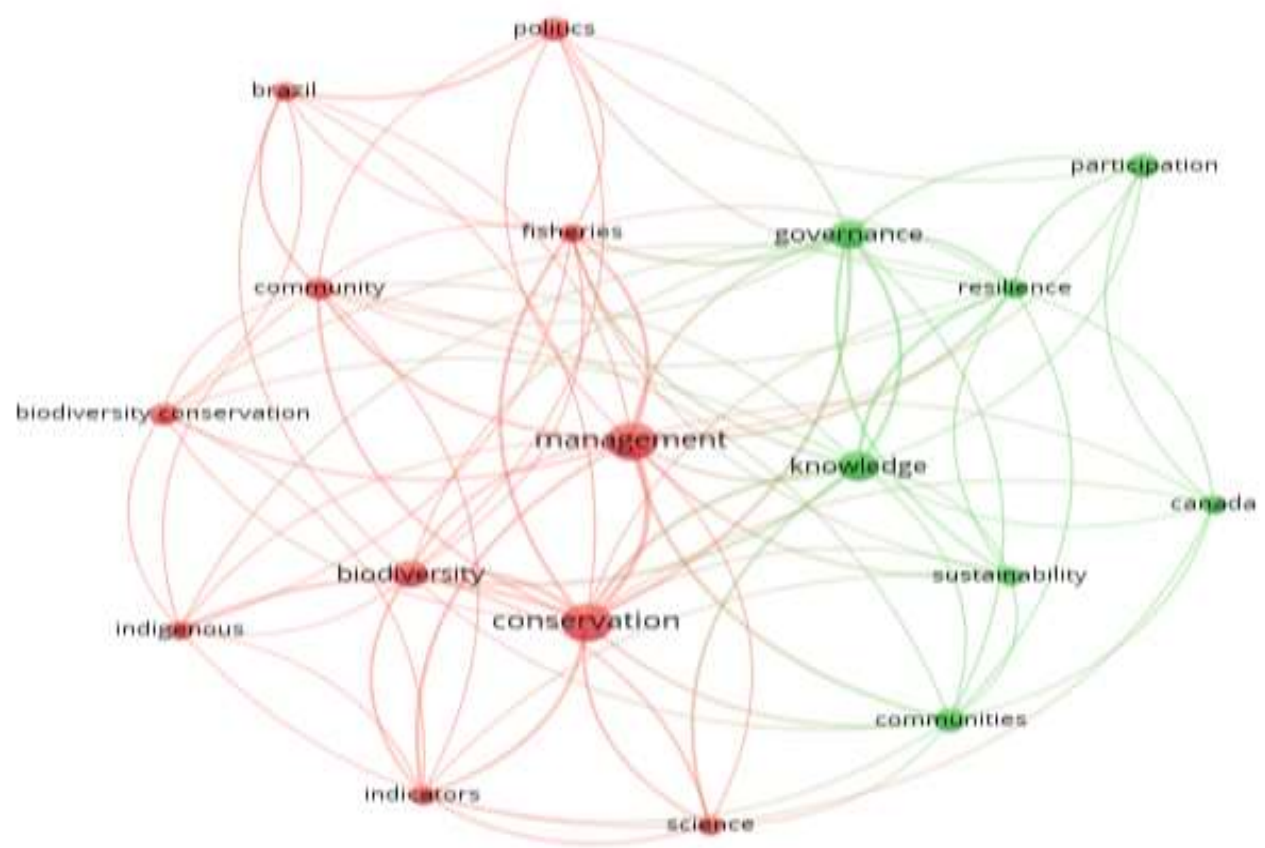

Fonte: Elaborado pelos autores (2021).

Na Figura 8, aparecem as palavras-chave e seu número de ocorrência, o que se constata ao observar a relação de força no cluster através das ligações estabelecidas. No cluster 1, onde aparece conservation, management e biodiversity em destaque, percebe-se que as publicações ali apresentadas levam em consideração a gestão voltada para a conservação da 
biodiversidade. Nesse cluster também aparece a palavra Brazil, demonstrando mais uma vez a posição estratégica do Brasil nesta área, dada sua diversidade sociobiocultural.

No cluster 2, destacam-se as palavras knowledge e governance, no qual constam pesquisas que destacam a importância de reconhecer os conhecimentos desenvolvidos pelas comunidades, isto é, os conhecimentos tradicionais, e a necessidade de integrá-los ao conhecimento científico na gestão ambiental. Outra palavra-chave que aparece nesse cluster é Canada, podendo significar que as pesquisas desenvolvidas com as comunidades daquele país levam mais em consideração essa perspectiva de aliar os conhecimentos produzidos na comunidade e fora dela, além de parecer focar mais na governança que na gestão, visto que ainda neste cluster a palavra governance aparece em destaque.

As três palavras-chave com mais ocorrências - manegement, conservation e knowledge - aparecem de forma bastante próxima, sugerindo uma forte interligação.

\section{Considerações Finais}

A análise de produção acadêmica sobre gestão ambiental e sua relação com as comunidades tradicionais, utilizando a base de dados Web of Science e o Vosviewer, mostrou como existe uma diversidade de análises acerca deste tema em todo o mundo, mais especificamente nos EUA, Brasil, Canadá e Austrália, de onde pode-se destacar o papel de protagonismo do Brasil, responsável pela maior quantidade de publicações por país na pesquisa da $W o S$, além de aparecer como o segundo país em citações e nas ocorrências de palavras-chave no Vosviewer.

Outro ponto relevante a ser observado é que a correlação de força entre os autores não foi tão forte. Contudo, pôde-se observar os autores de maior relevância através da quantidade de citações que estes possuem, com destaque para os autores Berkes, F. e Hill, R. (2012) Nesse sentido, aparece como limitação da pesquisa o fato de não haver ali uma grande relação de força entre os autores, o que evidencia uma rede fraca, demonstrando a necessidade de mais pesquisas nessa área, com mais autores dialogando entre si.

$\mathrm{Na}$ análise das palavras-chave, as que mais apareceram foram gestão, conservação, conhecimento e biodiversidade, o que demonstra que, ao tratar da gestão ambiental nas comunidades tradicionais, o foco maior é na manutenção da biodiversidade pelo reconhecimento dos saberes apresentados por aqueles povos. Portanto, percebe-se que uma gestão que tenha como foco o manejo sustentável de recursos naturais, quando se trata de lidar com territórios onde estão presentes povos e comunidades tradicionais, seu papel não deve ser os isolar nem os excluir, mas, por outro lado, compreender o papel de protagonismo destes grupos.

Em síntese, esta pesquisa permitiu identificar lacunas que podem ser sanadas com pesquisas futuras, levando em consideração o que foi identificado em outros países e que pode ser empregado em pesquisas no Brasil, especialmente no sentido de fomentar políticas públicas que retirem a compreensão do lugar de "gestor" como algo alheio e estranho, mas de reconhecimento de que estes povos e comunidades tradicionais carregam em sua essência o real comprometimento com a sustentabilidade, podendo trazer soluções, através de seus conhecimentos, para os problemas socioambientais do país.

Sendo assim, pesquisas que relacionem gestão ambiental e povos tradicionais podem trazer mais contribuições que versem acerca do reconhecimento do protagonismo dessas comunidades na gestão ambiental, discutindo suas práticas e conhecimentos tradicionais, sua conexão com o território ao qual pertencem e investigando o que os gestores públicos e privados têm feito no sentido de preservar essa sociobiodiversidade. 


\section{Referências}

Adorno, E., Bah, H. A. F., Bandeira, M. J., Gomes-Junior, E. A., Anjos, A. L. S., Rodrigues, Y. J. M., dos Santos, N. R., Martinez, V. O., Rocha, R. B. M. A., Costa, R. G. V., \& Menezes-Filho, J. A. (2020) Environmental exposure to lead and hematological parameters in Afro-Brazilian children living near artisanal glazed pottery workshops. Journal of environmental science and health part a-toxic/hazardous substances \& environmental engineering. 55 (08), 964-974. https://doi.org/10.1080/10934529.2020.1761738

Albert, G., Tschirhart, C., Mistry, J., Berardi, A., Bignante, E., Simpson, M., Haynes, L., Benjamin, R., Xavier, R., Robertson, B., Davis, O., Verwer, C., de Ville, G., \& Jafferally, D. (2016) Learning from one another: evaluating the impact of horizontal knowledge exchange for environmental management and governance. Ecology and Society. 21 (02), 41. https://doi.org/ 10.5751/ES-08495-210241

Brasil. Decreto n. 6040, de 07 de fevereiro de 2007 (2007). Institui a Política Nacional de Desenvolvimento Sustentável dos Povos e Comunidades Tradicionais. http://www.planalto.gov.br/ccivil_03/_ato2007-2010/2007/decreto/d6040.htm

Brasil. Constituição da República Federativa do Brasil. (1988). Senado Federal: Centro Gráfico.

Brasil. Convenção n. 169 sobre povos indígenas e tribais e Resolução referente à ação da OIT (2011). Brasília: OIT.

Brunsell, N. A., Cochran, F. V., Cabalzar, A., van der Veld, P., Azevedo, E.; Azevedo, R. A., Pedrosa, R. A., \& Winegar, L. J. (2016) Indigenous ecological calendars define scales for climate change and sustainability assessments. Sustainability Science, 11 (01), 69 - 89. https://doi.org/10.1007/s11625-015-0303-y

Da Silva, C. J., Albernaz-Silveira, R., \& Nogueira, P. S. (2014). Perceptions on climate change of the traditional community Cuiaba Mirim, Pantanal Wetland, Mato Grosso, Brazil. Climatic change. 127(01), 83-92. https://doi.org/ 10.1007/s10584-014-1150-z

De Sousa, D. N. (2020) Quilombolas and indigenous: analysis of family agriculture audiences excluded from public policies in a region of the legal amazon. Humanidades \& Inovação, 7 (16), 405 - 416. https://revista.unitins.br/index.php/humanidadeseinovacao/article/view/2915/1886

Diegues, A. C. S. (2000) O mito moderno da natureza intocada. USP.

Feitosa, M. O., Gomes, M. E. A., Fontoura, I. G., Pereira, C. S., Carneiro, A. M. C. T., Oliveira, M. C., Viana, J. A., Fontoura, V. M., Silva, K. C., Ribeiro, R. S., Vieira, P. C. S., Leite, S. G. V., Leal, L. P. A., Feitosa, A. N. A., \& Fonseca, F. L. A. (2021) Access to Health Services and Assistance Offered to the AfroDescendant Communities in Northern Brazil: A Qualitative Study. International Journal of Environmental Research and Public Health. 18 (02), 368. https://doi.org/10.3390/ijerph18020368

Gomes, M. F. L., \& Sampaio, J. A. (2019). Biopiracy and traditional knowledge: faces of biocolonialism and his regulation. Veredas do direito, 16 (34) 91 121. https://doi.org/10.18623/rvd.v16i34.1274

Hill, R., Grant, C., George, M., Robinson, C. J., Jackson, S., \& Abel, N. (2012) A Typology of Indigenous Engagement in Australian Environmental Management: Implications for Knowledge Integration and Social-ecological System Sustainability. Ecology and Society. 17(01), 23. https://doi.org/10.5751/ES-04587-170123

Idrobo, C. J., \& Berkes, F. (2012) Pangnirtung Inuit and the Greenland Shark: Co-producing Knowledge of a Little Discussed Species. Human ecology, 40(03), 405-414. https://doi.org/10.1007/s10745-012-9490-7

Madruga Filho, V. J. P., Santos, S. S., Nunes, G. M., Ferreira, E. C., Brasileiro, D. P., \& Lucena, R. F. P. (2018) Comunidades tradicionais: um olhar sob a ótica das políticas públicas. Revista Brasileira de Gestão Ambiental e Sustentabilidade. 05(10), 539-548. https://doi.org/10.21438/rbgas.051009

Silva, M. O. (2007). Saindo da invisibilidade - a política nacional de povos e comunidades tradicionais. Inclusão social. 02 (02), 7 - 9. http://revista.ibict.br/inclusao/article/view/1596

Thum, C. (2017) Povos e Comunidades tradicionais: aspectos históricos, conceituais e estratégias de visibilidade. REMEA. Edição especial. 162-179. https://doi.org/10.14295/remea.v0i0.6899

Toledo, V. M. (1999) Indigenous Peoples and Biodiversity. Encyclopedia of Biodiversity. Academic Press. 3, p. 451-463. https://doi.org/10.1016/B978-0-12$384719-5.00299-9$

Van Eck, N. J., \& Waltman, L. (2017) Citation-based clustering of publications using CitNetExplorer and VOSviewer. Scientometrics, 111 (01), 1053-1070. https://doi.org/10.1007/s11192-017-2300-7

Vanti, N. A. P. (2002) Da bibliometria à webometria: uma exploração conceitual dos mecanismos utilizados para medir o registro da informação e a difusão do conhecimento. Ciência da Informação, 31 (02), 152-162. https://doi.org/10.1590/S0100-19652002000200016

Welch, J. R., Brondizio, E. S., Hetrick, S. S., \& Coimbra, C. E. A. (2013) Indigenous Burning as Conservation Practice: Neotropical Savanna Recovery amid Agribusiness Deforestation in Central Brazil. Plos One, 8 (12) https://doi.org/10.1371/journal.pone.0081226 